\title{
Gas-discharge induced flash sintering of YSZ ceramics at room temperature
}

\author{
Yuchen $\mathrm{ZHU}^{a}$, Hongyang $\mathrm{ZHOU}^{a}$, Rongxia $\mathrm{HUANG}^{b}$, Nianping $\mathrm{YAN}^{c}$, \\ Xilin WANG ${ }^{a,}{ }^{*}$, Guanghua LIU $^{d}$, Zhidong JIA ${ }^{a}$ \\ ${ }^{a}$ Engineering Laboratory of Power Equipment Reliability in Complicated Coastal Environments, \\ Tsinghua Shenzhen International Graduate School, Tsinghua University, Shenzhen 518055, China \\ ${ }^{b}$ School of Electromechanical Engineering, Guangdong University of Technology, Guangzhou 510006, China \\ ${ }^{c}$ State Grade Jiangxi Electric Power Research Institute, Nanchang 330000, China \\ ${ }^{d}$ State Key Laboratory of New Ceramics and Fine Processing Tsinghua University, School of \\ Materials Science and Technology, Tsinghua University, Beijing 100084, China
}

Received: July 22, 2021; Revised: November 22, 2021; Accepted: December 4, 2021

(C) The Author(s) 2021.

\begin{abstract}
This is the first study to conduct the flash sintering of $3 \mathrm{~mol} \%$ yttria-stabilized zirconia (3YSZ) ceramics at room temperature $\left(25^{\circ} \mathrm{C}\right)$ under a strong electric field, larger than $1 \mathrm{kV} / \mathrm{cm}$. At the standard atmospheric pressure $(101 \mathrm{kPa})$, the probability of successful sintering is approximately half of that at low atmospheric pressure, lower than $80 \mathrm{kPa}$. The success of the proposed flash sintering process was determined based on the high electric arc performance at different atmospheric pressures ranging from 20 to $100 \mathrm{kPa}$. The $3 \mathrm{YSZ}$ samples achieved a maximum relative density of $99.5 \%$ with a grain size of $\sim 200 \mathrm{~nm}$. The results showed that as the atmospheric pressure decreases, the onset electric field of flash sintering decreases, corresponding to the empirical formula of the flashover voltage. Moreover, flash sintering was found to be triggered by the surface flashover of ceramic samples, and the electric arc on the sample surfaces floated upward before complete flash sintering at overly high pressures, resulting in the failure of flash sintering. This study reveals a new method for the facile preparation of flash-sintered ceramics at room temperature, which will promote the application of flash sintering in the ceramic industry.
\end{abstract}

Keywords: flash sintering; yttria-stabilized zirconia (YSZ); room temperature; flashover; AC field; low atmospheric pressure

\section{Introduction}

Flash sintering is a novel field-assisted sintering technique (FAST) discovered by Cologna et al. [1] in 2010. During

\footnotetext{
* Corresponding author.

E-mail: wang.xilin@sz.tsinghua.edu.cn
}

flash sintering, ceramic samples are subjected to a moderate electric field and current flows through ceramics. In this process, ceramics can be densified more rapidly (usually in $<5 \mathrm{~min}$ ) at furnace temperatures several hundred degrees lower than that utilized during traditional sintering. Various materials such as ionic conductors, semiconductors, and insulators have been successfully prepared by flash sintering or other FASTs 
[2-9].

Yttria-stabilized zirconia (YSZ) has a wide range of applications such as electrolytes and barriers [10-15]. It is also the most widely studied material in flash sintering research. DC power is more commonly used than AC for the flash sintering of YSZ. Many researchers have attempted to lower the onset temperature of YSZ by increasing the electric field power in both DC and AC flash sintering [16]. Downs and Sglavo [17] succeeded in flash sintering cubic $8 \%$ mol yttriastabilized zirconia (8YSZ) at $390{ }^{\circ} \mathrm{C}$ under a $2.25 \mathrm{kV} / \mathrm{cm}$ DC field and a $120 \mathrm{~mA}$ current; however, the linear shrinkage of the sintered samples reached only $8.5 \%$. Yadav and Raj [18] induced flash sintering on dense $3 \mathrm{YSZ}$ and $8 \mathrm{YSZ}$ polycrystals at $6.00 \mathrm{kV} / \mathrm{cm} \mathrm{DC}$ and $180{ }^{\circ} \mathrm{C}$ furnace temperature (approaching its Debye temperature limit), inducing the strongest electric field ever utilized for this process. Liu et al. [19] sintered $8 \mathrm{YSZ}$ to $95.3 \%$ relative density under an AC field of $2760 \mathrm{~V} / \mathrm{cm}$ and at $420{ }^{\circ} \mathrm{C}$. Steil et al. [20] sintered $8 Y$ YSZ pellets to $80 \%$ relative density with a $300 \mathrm{~V} / \mathrm{cm}$ AC field at $800{ }^{\circ} \mathrm{C}$, while the electric field strength in other AC flash sintering experiments of YSZ is lower than $200 \mathrm{~V} / \mathrm{cm}$ [10,21-27]. Currently, the Debye temperature is still regarded as the lower bound of flash sintering for YSZ [28]. Moreover, thus far, there have been no reports on flash sintering of YSZ at room temperature.

Biesuz et al. [29] and Shi et al. [30] found a correlation between dielectric breakdown and flash sintering. According to Liu et al. [31], the dielectric breakdown under AC can trigger the flash sintering of zinc oxide at room temperature (lower than its Debye temperature of approximately $166.85{ }^{\circ} \mathrm{C}$ ), and they reported the highest relative density of sintered zinc oxide of $99 \%$ [31,32]. These results indicate that flash sintering induced by AC dielectric breakdown is likely to facilitate the formation of dense YSZ ceramic samples at furnace temperature lower than their Debye temperature (the Debye limit temperature of YSZ ceramics ranges from 176.85 to $251.85{ }^{\circ} \mathrm{C}$ ) [18].

Several studies on flash sintering in different gas environments have been reported. Liu et al. [33] found that a lower oxygen partial pressure leads to a higher concentration of electrons and oxygen vacancies in YSZ, which will boost its conductivity and reduce its flash sintering onset voltage. Zhang and Luo [34] proved that in a reduced atmosphere $\left(\mathrm{Ar}+5 \% \mathrm{H}_{2}\right)$, the flash sintering of zinc oxide can occur at a temperature lower than $120{ }^{\circ} \mathrm{C}$ in a $1000 \mathrm{~V} / \mathrm{cm}$ electric field. Therefore, the atmospheric environment is a key parameter in flash sintering. According to Paschen's law, the dielectric breakdown voltage of an air gap decreases with pressure when the product of gap length and pressure is higher than $0.5 \mathrm{~cm} \cdot \mathrm{mmHg}$. The surface breakdown (flashover) voltage of insulators decreases as the atmospheric pressure decreases [35-37]. Hence, in flash sintering at low pressure, the lower onset voltage of the flashover possibly facilitates flash sintering.

In this study, an AC power source was used, and we discovered that the relative densities of the 3 YSZ samples can be increased to $99 \%$ by flash sintering at room temperature for $30 \mathrm{~s}$. The surface flashover phenomenon in the flash sintering process was also discussed.

\section{Experimental methods}

High-purity 3 YSZ powder ( $>99 \%$, average grain size 30 nm, Nanjing Mission New Materials Company Limited, Nanjing, China) was blended with a binder through spray-drying granulation. The mixture was uniaxially pressed into dog-bone-shaped samples at $270 \mathrm{MPa}$, and the sample dimensions are shown in Fig. 1(a). The green bodies of the YSZ samples were then heated in a furnace to $400{ }^{\circ} \mathrm{C}$ at a heating rate of $2{ }^{\circ} \mathrm{C} / \mathrm{min}$, and maintained at this temperature for $2 \mathrm{~h}$ for binder removal through drying. Next, the samples were presintered at $1100{ }^{\circ} \mathrm{C}$ for $2 \mathrm{~h}$ at a heating rate of $2{ }^{\circ} \mathrm{C} / \mathrm{min}$ to enhance their strength. Finally, high-temperature GW02 silver paste was painted on both ends of the dogbone-shaped ceramics to decrease contact resistance with the circuit. Painted samples were baked at $650{ }^{\circ} \mathrm{C}$ for $10 \mathrm{~min}$ for silver consolidation. The samples sintered in this experiment were denoted as S20-S100, as listed in Table 1.

The flash sintering setup is shown in Fig. 1(b). The 3 YSZ samples were placed in a vacuum chamber, and connected to a high-voltage AC test power source (50 Hz, DTW-100/50, Xinyuan Electric Company, China) through $0.5 \mathrm{~mm}$ radius platinum wires. The capacity, maximum output voltage, and rated output current of the test power source were $100 \mathrm{kV} \cdot \mathrm{A}, 50 \mathrm{kV}$, and $1 \mathrm{~A}$, respectively. This test power supply was typically used in high-voltage engineering applications. A corundum board was placed between the ceramic samples and the bottom of the vacuum chamber for insulation. Our test power source cannot limit the current automatically. 


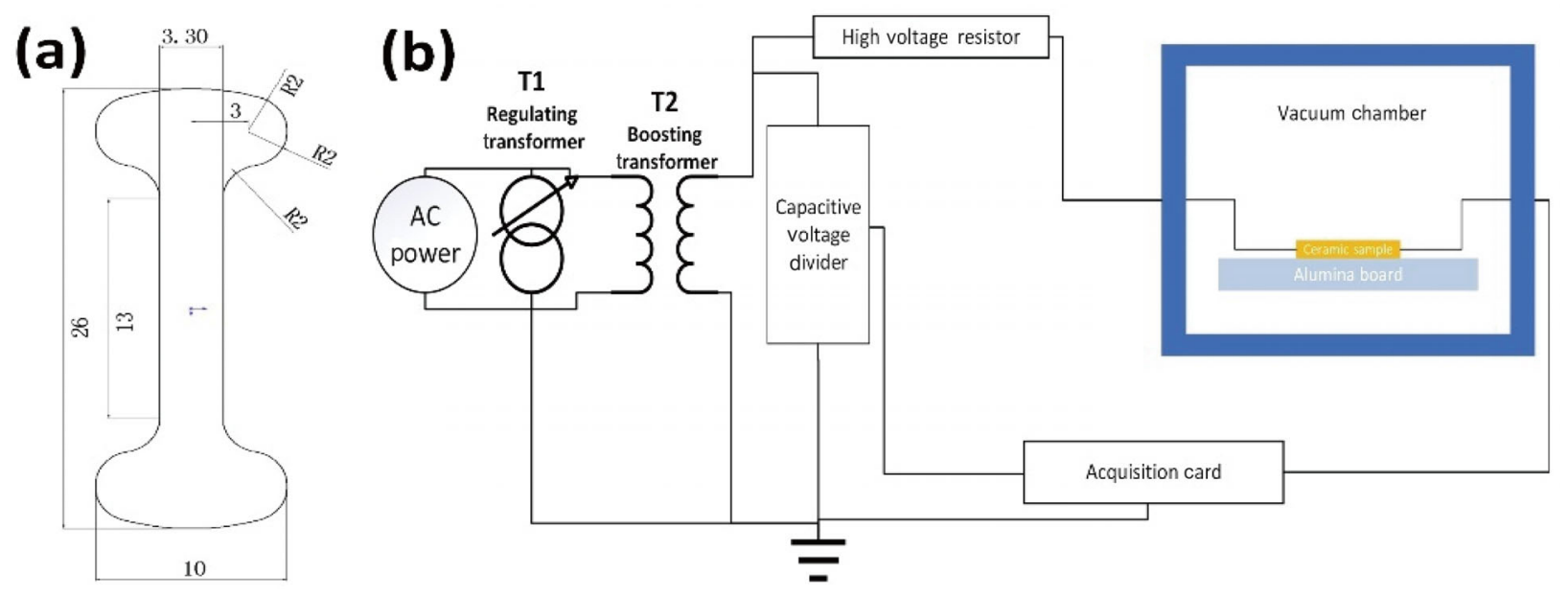

Fig. 1 (a) Dimensions of our dog-bone-shaped sample (in $\mathrm{mm}$ ). (b) Flash sintering experiment setup.

High-voltage resistors, whose total resistance varies from 0 to $20 \mathrm{k} \Omega$, were also added into the circuit to limit the current in the experiment.

The pressure inside the vacuum chamber was adjusted to the standard values after connecting the circuit. Because of the use of the air pump, the lowest barometric pressure in the chamber used in this study was $20 \mathrm{kPa}$. The $50 \mathrm{~Hz}$ high-voltage test power supply was turned on to initiate the flash sintering experiment on YSZ. The $50 \mathrm{~Hz}$ AC power was controlled manually, and its initial output voltage was $\sim 0.9 \mathrm{kV}$. The output voltage was increased in small increments until the current surged, which signified the onset of flash sintering. The average rising rate of the voltage was maintained at $<0.4 \mathrm{kV} / \mathrm{s}$ to prevent voltage surge from increasing the onset voltage. After the flash sintering process started, the current was maintained for $30 \mathrm{~s}$ before the output of the test source was lowered to a minimum and turned off.

The output voltage and current variations were recorded using an acquisition card with an acquisition rate of $5000 \mathrm{~Hz}$. The voltage, current, electric field, current density, and power density mentioned here were root-mean-square values. The video of the YSZ samples during flash sintering was recorded by a high-speed camera (Phantom V2012). The exposure time of all the images recorded by the high-speed camera shown in Figs. 3-5 was set lower than $100 \mu \mathrm{s}$ to capture the electric arc whose light emission was extremely strong. This means the light of normal intensity cannot be recorded. The relative densities of all samples were measured by Archimedes drainage. The crystalline structures of the YSZ ceramic samples were determined through X-ray diffraction (XRD) analysis (D8 Advance, Bruker, Germany). Scanning electron microscopy (SEM; SU8010, Hitachi, Japan) was conducted to acquire high-resolution microstructure images of the sample and fracture surfaces. The surfaces of samples S20, S60, and S100 were polished and thermally etched at $1300{ }^{\circ} \mathrm{C}$ for $30 \mathrm{~min}$ before being observed by SEM.

\section{Results and discussion}

\section{1 Variations of electrical parameters during flash sintering}

Table 1 summarizes the experimental conditions of typical 3YSZ flash sintering experiments. The onset electric field, flash current density, and relative density are listed with different pressures used in the experiment. The estimated temperatures in the steady state were acquired using black body radiation models [38].

Table 1 Main parameters of 3YSZ flash sintering experiments

\begin{tabular}{|c|c|c|c|c|c|c|}
\hline Sample & $\begin{array}{c}\text { Pressure } \\
(\mathrm{kPa})\end{array}$ & $\begin{array}{c}\text { Onset } \\
\text { field } \\
(\mathrm{kV} / \mathrm{cm})\end{array}$ & $\begin{array}{c}\text { Flash } \\
\text { current } \\
\text { density } \\
\left(\mathrm{mA} / \mathrm{mm}^{2}\right)\end{array}$ & $\begin{array}{c}\text { Power } \\
\text { density } \\
\left(\mathrm{mW} / \mathrm{mm}^{3}\right)\end{array}$ & $\begin{array}{c}\text { Relative } \\
\text { density } \\
(\%)\end{array}$ & $\begin{array}{l}\text { Estimated } \\
\text { temperature } \\
\left({ }^{\circ} \mathrm{C}\right)\end{array}$ \\
\hline S20 & 20 & 2.06 & 40.6 & 1033 & 97.1 & 1906 \\
\hline S40 & 40 & 4.35 & 50.8 & 2204 & 99.5 & 2361 \\
\hline S60 & 60 & 5.01 & 58.9 & 2738 & 99.2 & 2508 \\
\hline S 80 & 80 & 6.49 & 52.6 & 2456 & 98.7 & 2433 \\
\hline S100-1 & 100 & 7.45 & $\begin{array}{c}60.0 \\
\text { (arc-float) }\end{array}$ & 3222 & 71.2 & - \\
\hline $\mathrm{S} 100-2$ & 100 & 8.92 & 49.8 & 2252 & 97.7 & 2375 \\
\hline
\end{tabular}


Compared with other studies, our estimated temperatures are much higher because of the high steady state power $[1,5,19,34,39]$.

Figure 2 shows the variations in the electric field, current density, and power density during the flash sintering process of S60, which is similar to those of the remaining samples. The electric field strength is increased gradually, and the current density is maintained at an extremely low level during the incubation stage. A flash sintering event occurs when the electric field exceeds a certain level, during which an abrupt increase in the current density occurs, and the electric field suddenly drops. After the flash event, the electric field stabilizes at a low value, and the current density remains unchanged until the electric power is turned off. The power density of the 3YSZ sample surges to its maximum when flash sintering occurs and gradually decreases to a lower value at the steady rate. Although the variation tendency of the electrical parameters described in Fig. 2 coordinates with the findings of previous flash sintering studies, the visual phenomenon in our flash sintering experiment is very different from that reported in other studies [40], as shown in Fig. 3.

\section{2 Flash sintering at standard atmosphere pressure}

Two phenomena occur during the flash sintering process at the standard atmospheric pressure, as shown in Figs. 3 and 4. The " 0 s" in Figs. 3 and 4 corresponds to the moment when current surge point as Fig. 2 demonstrates. With sample S100-1 (Fig. 3), the arc appeared but no flash sintering occurred. Moreover, with sample S100-2 (Fig. 4), the arc first appeared, then disappeared, and finally flash sintering occurred. When the flash current density reaches $60.0 \mathrm{~mA} / \mathrm{mm}^{2}$ at $100 \mathrm{kPa}$, flash sintering fails owing to the floating up of the electric arc, as shown in Fig. 3. After flashover occurs (Fig. 3(b)), the electric arc does not induce global flash sintering, and only floats over the ceramic samples during the entire $30 \mathrm{~s}$ process, as demonstrated in Figs. 3(b)-3(d). Therefore, even if ceramic sintering does not appear, the arc-floating phenomenon indicates that an electric arc appears in our flash sintering experiments.

Figure 4(a) shows the S100-2 green body without sintering, and Figs. 4(b)-4(f) present snapshots captured at $0,1.78,5.50,10.69,11.30,13.50$, and $17.45 \mathrm{~s}$ after the onset of flash sintering at $100 \mathrm{kPa}$, close to the standard atmosphere pressure. At the beginning of the flash sintering process, as shown in Fig. 4(b), the surface flashover occurs, and an electric arc appears above the sample. Considering that the onset voltage indicated in Fig. 2 is much lower than the
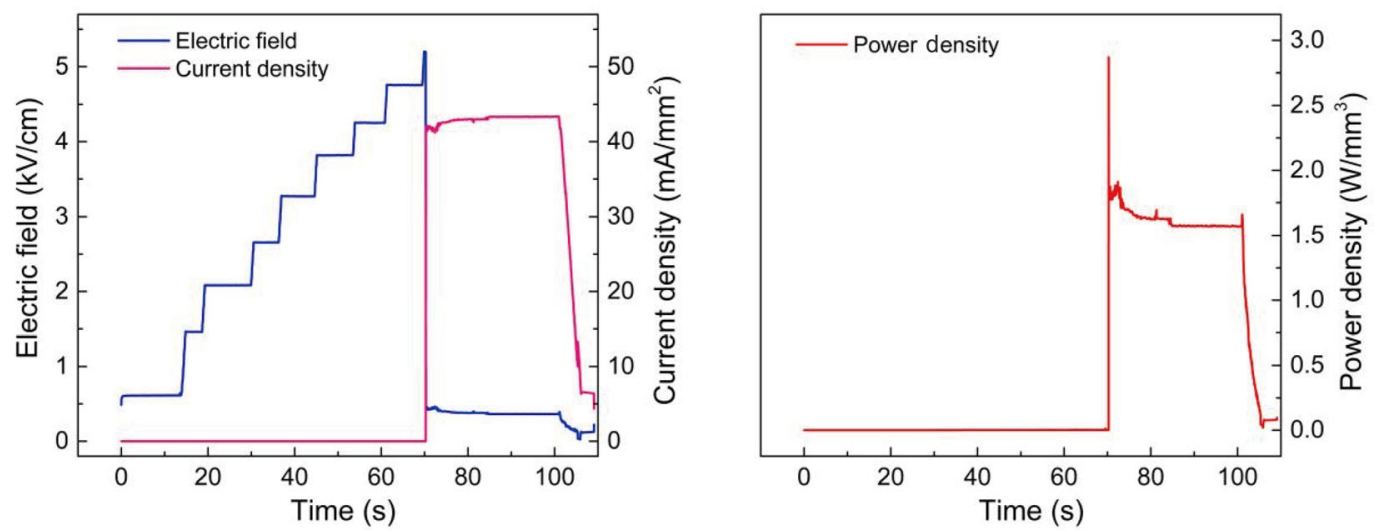

Fig. 2 Electric field, current density, and power density variations during flash sintering of sample S60.

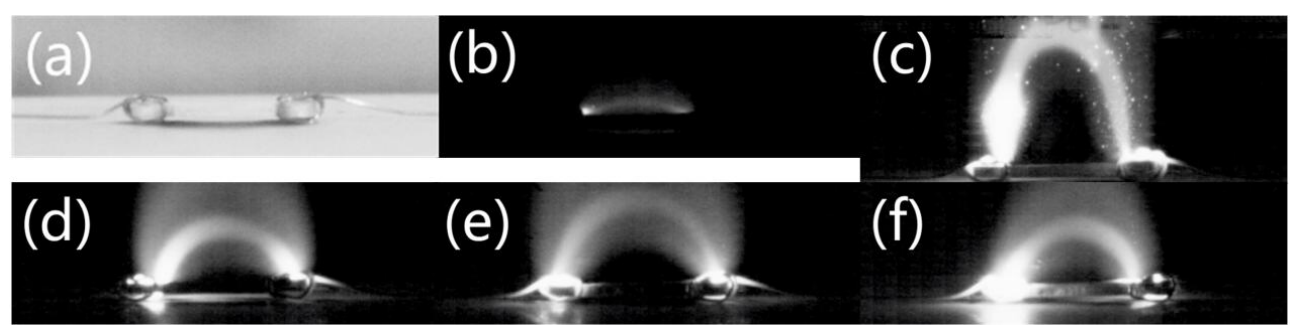

Fig. 3 Snapshots recorded using a high-speed camera during the flash sintering of S100-1: (a) before flash sintering and at (b) $0 \mathrm{~s}$, (c) $2.16 \mathrm{~s}$, (d) $10.09 \mathrm{~s}$, (e) $20.04 \mathrm{~s}$, and (f) $30.07 \mathrm{~s}$ after the onset of current surge at a current density of $60.0 \mathrm{~mA} / \mathrm{mm}^{2}$. 


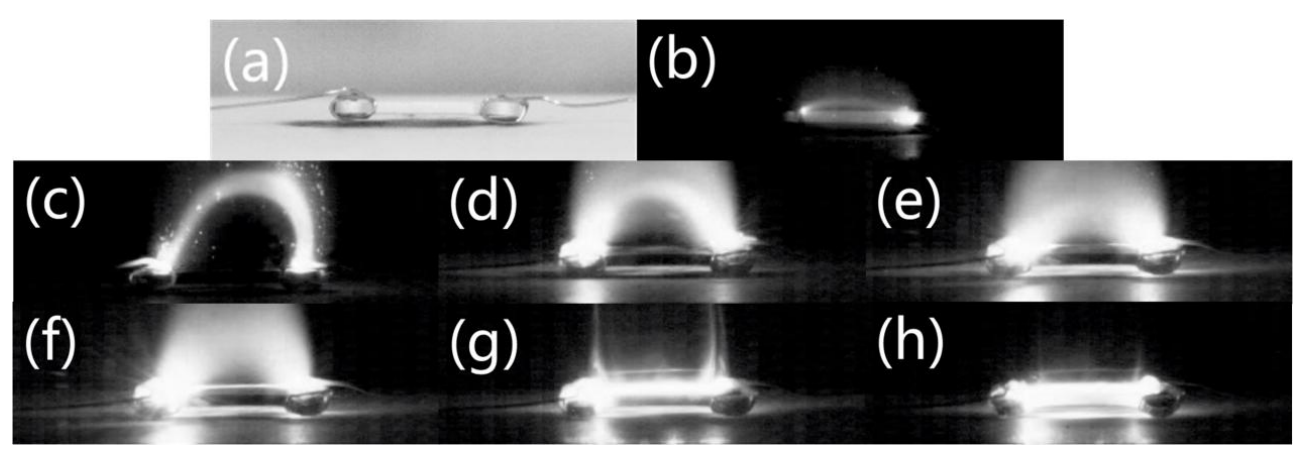

Fig. 4 Snapshots recorded using a high-speed camera during the flash sintering of S100-2: (a) before flash sintering and at (b) $0 \mathrm{~s}$, (c) $1.78 \mathrm{~s}$, (d) $5.50 \mathrm{~s}$, (e) $10.69 \mathrm{~s}$, (f) $11.30 \mathrm{~s}$, (g) $13.50 \mathrm{~s}$, and (h) $17.45 \mathrm{~s}$ after the onset of flash sintering, with a current density of $49.8 \mathrm{~mA} / \mathrm{mm}^{2}$.

breakdown voltage of the air gap, and the arc appears outside the sample, this phenomenon is very likely to be surface flashover rather than air gap breakdown inside the sample. (Surface flashover is a special kind of air gap breakdown. It happens in the air gap very close to the dielectric surface, where the electric field is strongly intensified, so its breakdown voltage is much lower.) Figure 4(b) presents the moment when the current density surges, as shown in Fig. 2. In the first $10 \mathrm{~s}$ after the flash onset, the electric arc produced by the flashover floats above the upper surface of the sample, and there is no indication of flash sintering. Then, two glowing areas develop from both ends of the sample (Fig. 4(e)), and connect with each other on the upper part of the sample (Fig. 4(f)). The glowing area covers the entire upper part $13.50 \mathrm{~s}$ after the flash onset (Fig. 4(g)), and the electric arc disappears, which indicates that the current starts to completely flow through the upper part of the sample. Finally, the glowing area expands to the entire sample, indicating the start of global flash sintering (Fig. 4(h)). The entire process, from the onset of flashover to global flash sintering (Figs. 4(b)-4(g)), takes more than $15 \mathrm{~s}$ at 100 $\mathrm{kPa}$. The total flash sintering time, after Fig. 4(h), is only approximately $12.55 \mathrm{~s}$.

The arc-floating performances in S100-1 and S1002 are different; thus, the later sintering behavior in both samples is affected. Obviously, there are two current paths during the whole sintering process, one in the arc and the other in the sample. Most of the currents flow through the electric arc when surface flashover happens. After a period of time, as the electric arc heats the upper part of the 3YSZ ceramics, the conductivity of the upper part of the $3 \mathrm{YSZ}$ ceramics increases, making more currents flow through the upper part. With larger current, the temperature of the upper part of the sample will be further boosted, improving its conductivity and leading to more current flowing through it. Under the impact of this positive feedback loop, partial flash sintering occurs, and more currents flow through the upper part of the $3 \mathrm{YSZ}$ samples, with currents of the electric arc decreasing gradually. Finally, currents of the electric arc descend to zero, and the arc disappears, and the only current path was through the sample, as shown in Figs. 4(f) and $4(\mathrm{~g})$. This indicates that, to successfully conduct flash sintering, the arc should be short-circuited by the current passing through the ceramic sample. Furthermore, the arc holding time in S100-2 was different from that in a previous study on $\mathrm{ZnO}$ ceramic sintering $(<1 \mathrm{~s})$ [31], and it was more than $10 \mathrm{~s}$ in S100-1 at standard pressure.

Therefore, we can conclude that flash sintering at $100 \mathrm{kPa}$ is triggered by the surface flashover. When the voltage reaches a certain level and the flashover occurs, the electric arc, whose temperature is very high, will dramatically increase the temperature of the upper surface of the $3 \mathrm{YSZ}$ samples. Higher temperatures will lead to larger conductivity, and higher conductivity will induce larger current, which will further increase the temperatures. This positive cycle can induce partial flash sintering on the upper part of the ceramic samples. Then, partial flash sintering continues this positive cycle, creates a current pathway in the upper part of samples, and short-circuits the electric arc, making all the currents flow through ceramic samples. Finally, the partial flash sintering expands to the entire sample, and the current flows through the whole sample, inducing complete flash sintering of the 3 YSZ samples. Ceramic samples are densified by the current flowing through them. According to the predictions of thermal radiation model [38], the ceramic samples reach more than $1500{ }^{\circ} \mathrm{C}$ in less than $20 \mathrm{~s}$ under the heating effect of current inside them. Therefore, the Joule heating as 
well as the ultrafast heating effect definitely contributes to the densification of the 3YSZ ceramic samples [41].

Anyway, despite the similarities of densification mechanisms, the onset mechanism of flash sintering proved in our study is very different from those previously reported such as those based on thermal runaway, Frenkel-pair nucleation, and electrochemical effects under DC voltage, in which the current flowing through the interior of the ceramic samples triggers flash sintering [38,42-44].

\section{3 Flash sintering under a low pressure of $60 \mathrm{kPa}$}

Arc floating is very problematic during 3YSZ flash sintering at pressures of $100 \mathrm{kPa}$. This is because if the current density when arc appearing is high, the effective sintering time is decreased, which can even lead to the failure of the flash sintering experiment. To address this problem and reduce the onset electric field, we conducted flash sintering experiments at low atmospheric pressures of $80,60,40$, and $20 \mathrm{kPa}$. The snapshots captured during flash sintering experiments of $\mathrm{S} 60$, which were conducted at $60 \mathrm{kPa}$, are shown in Fig. 5. The " $0 \mathrm{~s}$ " in Fig. 5 also corresponds to the moment when current surge as Fig. 2 demonstrates. The flash sintering processes of S20, S40, S60, and S80 are similar to that of $\mathrm{S} 100-2$, indicating that a similar onset mechanism. Therefore, it is reasonable to say that the flash sintering in our research is induced by the surface flashover of the $3 \mathrm{YSZ}$ samples.

In addition, there are still some differences between flash sintering at standard atmospheric pressure and low pressure. Based on the flash sintering process of S100-1 (Fig. 4) and S60 (Fig. 5), we find that with similar flash current densities of $\sim 60 \mathrm{~mA} / \mathrm{mm}^{2}$, flash sintering fails owing to the arc-floating issue at $100 \mathrm{kPa}$, but succeeds at $60 \mathrm{kPa}$. During the flash sintering of S100-2 (current density of $49.8 \mathrm{~mA} / \mathrm{mm}^{2}$ ) at $100 \mathrm{kPa}$, the time for arc floating was more than $10 \mathrm{~s}$, and the global sintering duration was only $12.55 \mathrm{~s}$. However, in S60 (current density of $58.9 \mathrm{~mA} / \mathrm{mm}^{2}$ ), the arc-floating time is less than $2 \mathrm{~s}$, and the complete flash sintering exceeds $27 \mathrm{~s}$. Therefore, by inhibiting the electric arc floating, conducting flash sintering at a low pressure can not only prevent flash sintering failure when the flash current density is high, but also decrease the transition time between the surface flashover and global flash sintering. Thus, roomtemperature flash sintering of $3 \mathrm{YSZ}$ at a low atmospheric pressure is possible.

Figure 6 shows the onset electric field variation at different pressures. Frywell et al. [37] reported that the relationship between the flashover voltage and atmospheric pressure can be determined by Eq. (1):

$$
U_{\mathrm{f}}=U_{0}\left(\frac{P}{P_{0}}\right)^{n}
$$

where $P_{0}$ is the standard atmospheric pressure $(\mathrm{kPa})$, $U_{0}$ is the flashover voltage at the standard atmospheric pressure $(\mathrm{V}), n$ is the influence index of the pressure, $P$ is the atmospheric pressure $(\mathrm{kPa})$, and $U_{\mathrm{f}}$ is the predicted flashover voltage at pressure $P$. If the sample geometry remains unchanged, this function can be written as

$$
E_{\mathrm{f}}=a P^{n}
$$

where $E_{\mathrm{f}}$ is the flashover electric field, and $a$ is a constant. Adopting Eq. (2) as a fitting function, the fitting result is achieved as that shown in Fig. 6. The adjusted $R$-square value of 0.9718 is higher than 0.95 , proving that the relation between the onset field and the barometric pressure can be expressed by this equation. As shown in Fig. 6, the onset electric field of flash

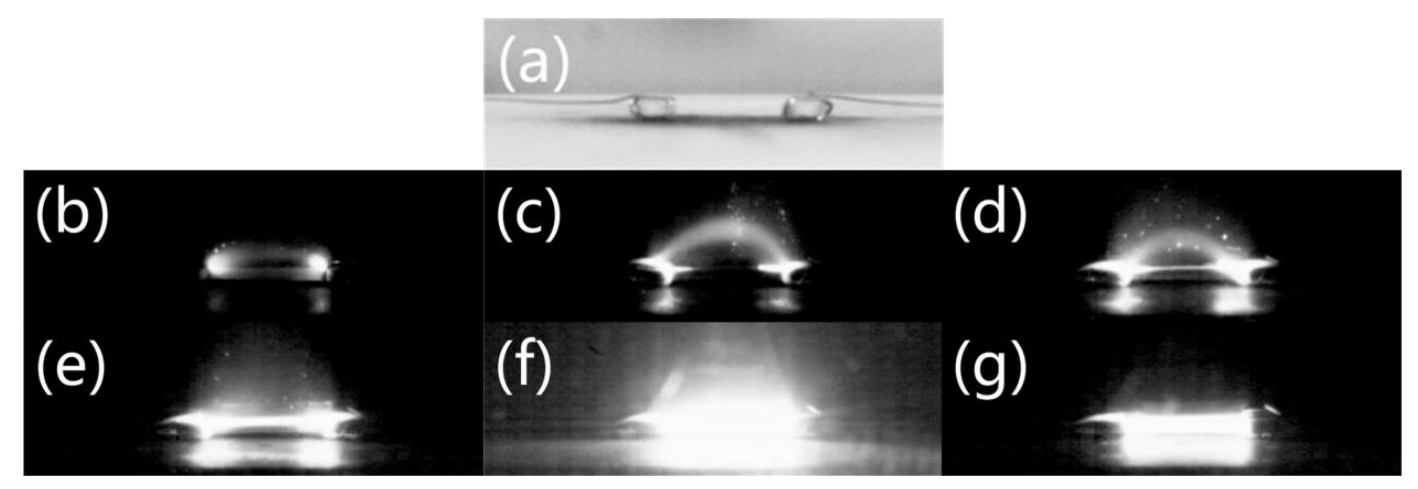

Fig. 5 Snapshots recorded using a high-speed camera during the flash sintering of S60: (a) before flash sintering and at (b) $0 \mathrm{~s}$, (c) $0.95 \mathrm{~s}$, (d) $1.70 \mathrm{~s}$, (e) $2.43 \mathrm{~s}$, (f) $2.90 \mathrm{~s}$, and (g) $15.20 \mathrm{~s}$ after the onset of flash sintering at a current density of $58.9 \mathrm{~mA} / \mathrm{mm}^{2}$. 
sintering would increase as the experimental atmosphere pressure increased. According to the previous research on the flashover of electrical insulators, the $n$ value lies in the range of 0.2-0.9 [45], and our $n$ value is 0.7693 , indicating that in our experiment, the influence of pressure on the flashover voltage is relatively strong.

\section{4 Short-time flash sintering}

To further confirm that flash sintering is induced by the electric arc of the surface flashover, an additional test was conducted. The experimental conditions (resistor

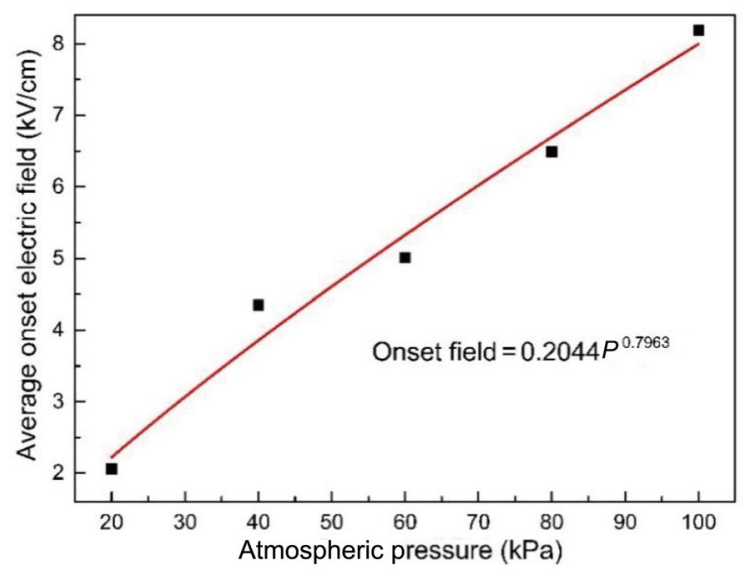

Fig. 6 Average onset electric field as a function of atmospheric pressure. value and atmospheric pressure) were the same as those used for the flash sintering of S60. After flash sintering, the power source was turned to a minimum and switched off immediately (in less than $2 \mathrm{~s}$ ). The relative density of this sample only reaches $70.0 \%$. The fractured surfaces of the sample sintered using this process were observed by SEM, as shown in Fig. 7. It can be seen that near the upper surface, on which flashover occurs, the microstructure was dense with only a few pores, and the grain sizes were larger. In the central part of this sample, a loose microstructure and pores and small grains were visible, indicating that the sintering was incomplete. The lower surface of the sample appeared to be the same as the green body of YSZ ceramics, and no obvious sintering was observed. These images show a different sintering process: The YSZ sample was sintered from the upper surface near the arc, then spread to the center, and finally to the lower surface. Therefore, the flash sintering process starts from the surface whereon flashover occurs, which confirms the proposed surface flashover mechanism.

\section{5 Explanation of electrical arc floating}

S100-1 was the only sample for which flash sintering failed. If the atmospheric pressure decreases to $80 \mathrm{kPa}$ similar to that for S80, a strong arc-floating phenomenon

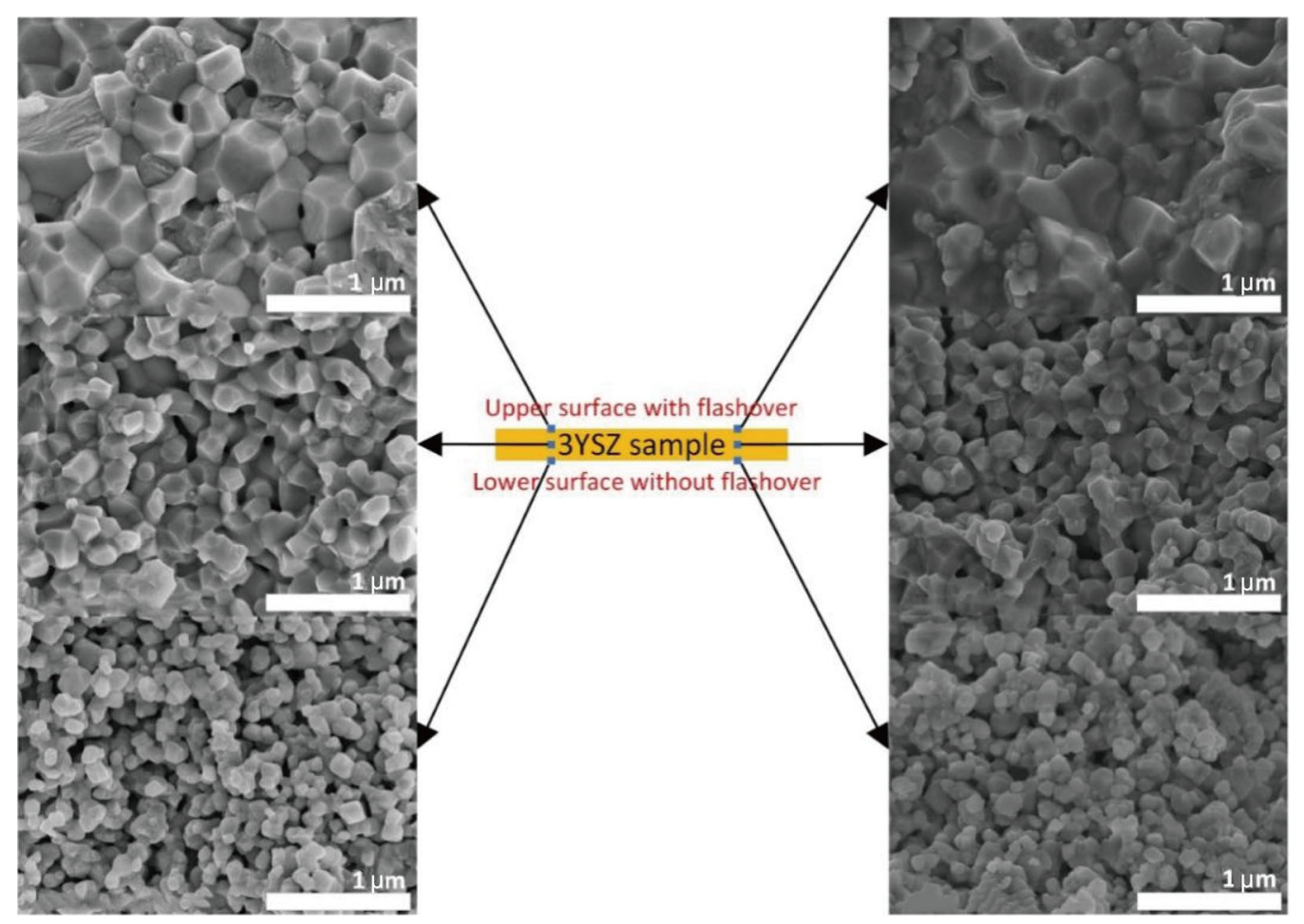

Fig. 7 SEM images of the fractured surfaces of 3 YSZ sample sintered for less than $2 \mathrm{~s}$. 
that leads to flash sintering failure will not occur; thus, higher atmospheric pressure promotes arc floating, as discussed below. The electric arc tends to move upward under the impact of thermal buoyancy [46]. The thermal buoyancy of the electric $\operatorname{arc}\left(F_{\mathrm{b}}\right.$, in $\left.\mathrm{N}\right)$ can be expressed by Eq. (3):

$$
F_{\mathrm{b}}=\rho \pi r_{\mathrm{a}}^{2} L
$$

where $\rho$ is the density of the ambient atmosphere $\left(\mathrm{kg} / \mathrm{mm}^{3}\right), r_{\mathrm{a}}$ is the radius of the electric $\operatorname{arc}(\mathrm{m})$, and $L$ is the length of the electric arc $(\mathrm{m})$, which remains constant in our study. The variations in $r_{\mathrm{a}}$ can be expressed as [47]:

$$
r_{\mathrm{a}}=\left(\frac{P}{P_{0}}\right)^{0.25} \sqrt{\frac{I_{\mathrm{m}}}{0.86 \pi}}
$$

where $P$ is the pressure of the ambient atmosphere $(\mathrm{kPa}), P_{0}$ is the standard atmospheric pressure $(\mathrm{kPa})$, and $I_{\mathrm{m}}$ is the maximum current of the electric arc (A). The $0.86 \pi$ denominator has a unit of $\mathrm{A} / \mathrm{m}^{2}$. The density of the ambient atmosphere $(\rho)$ can be determined by Eq. (5):

$$
\rho=\rho_{0} \frac{P}{P_{0}} \frac{293}{T}
$$

where $\rho_{0}$ is the density of the ambient atmosphere at the standard atmospheric pressure $\left(\mathrm{kg} / \mathrm{mm}^{3}\right)$, and $T$ is the temperature of the ambient atmosphere (K). Substituting Eqs. (3) and (4) into Eq. (1), we obtain the expression of thermal buoyancy per unit length as a function of ambient pressure and flash current:

$$
F_{\mathrm{b}}=\rho_{0}\left(\frac{P}{P_{0}}\right)^{1.5}\left(\frac{I}{0.86}\right)\left(\frac{293}{T}\right)
$$

According to Eq. (6), thermal buoyancy per unit of the electric arc increases when the flash current increases or when the experiments are conducted at high pressure, which inhibits both the electric arc from floating higher up and high-energy particles produced by discharge from reaching the upper surface of the samples. Thus, the thermal effects of the electric arc on the 3YSZ samples are weakened, lowering the temperature of the $3 \mathrm{YSZ}$ upper surface and inhibiting the development of partial flash sintering.

In addition, a higher atmospheric pressure leads to a higher oxygen partial pressure. Increased oxygen partial pressure can clearly reduce the conductivity of the 3YSZ samples [33], thereby hindering flash sintering. Heat convection intensifies at high pressure [48]. This will also suppress flash sintering by diluting the high-temperature particles produced by the electric arc, thereby decreasing the temperature of $3 \mathrm{YSZ}$.

\section{6 Structure and morphology of samples}

The XRD spectra of the samples are shown in Fig. 8 . According to Fig. 8(a), the powder of the 3 YSZ samples consists of a tetragonal phase and a monoclinic phase. After pre-sintering at $1100{ }^{\circ} \mathrm{C}$ for $2 \mathrm{~h}$, the monoclinic phase was removed from the green bodies of $3 \mathrm{YSZ}$, and only the tetragonal phase remained. The YSZ phase transitions between monoclinic and tetragonal and between tetragonal and cubic are all martensitic transformations. Although the martensitic phase transformation is reversible, the hysteresis effect induces a higher monoclinic to tetragonal transition temperature than tetragonal to monoclinic transition temperature [49]. According to Andrievskaya et al. [50] and Xie and Xue [51], the martensitic transformation temperature of 3 YSZ is approximately $600{ }^{\circ} \mathrm{C}$ for the monoclinic to tetragonal transition and lower than $-196.15{ }^{\circ} \mathrm{C}$ for the tetragonal to monoclinic transition. Thus, the monoclinic phase of $3 \mathrm{YSZ}$ becomes tetragonal during pre-sintering at $1100{ }^{\circ} \mathrm{C}$, and remains tetragonal when cooled to room temperature.

Figures $8(\mathrm{c})-8(\mathrm{e})$ also show that the flash-sintered samples only contain the tetragonal phase and not the monoclinic phase. To determine whether a cubic phase exists in the sintered 3YSZ samples, the XRD spectrum of S60, which has the maximum steady-state temperature, measured by slow scanning between $72^{\circ}$ and $75^{\circ}$, is shown in the inset of Fig. 8(d). No obvious peak was observed between the two peaks of the tetragonal phase, indicating very low content of the cubic phase. Thus, it is reasonable to state that the 3YSZ samples with a pure tetragonal phase are obtained after flash sintering, and negligible monoclinic or cubic phase is involved.

Figure 9(a) shows the surfaces of the green body before pre-sintering, and Figs. 9(b)-9(f) show the microstructures of the polished and thermally etched surfaces of the flash-sintered samples (thermal etching at $1300{ }^{\circ} \mathrm{C}$ for $30 \mathrm{~min}$ ). All SEM images were captured at the center of the polished surfaces of the samples, and the magnification factor was 45,000 . For a certain sample, the microstructures on the polished surface upon thermal etching were essentially the same at different locations. Nearly no pores are observed in Figs. 9(b)-9(f) because their relative densities are 


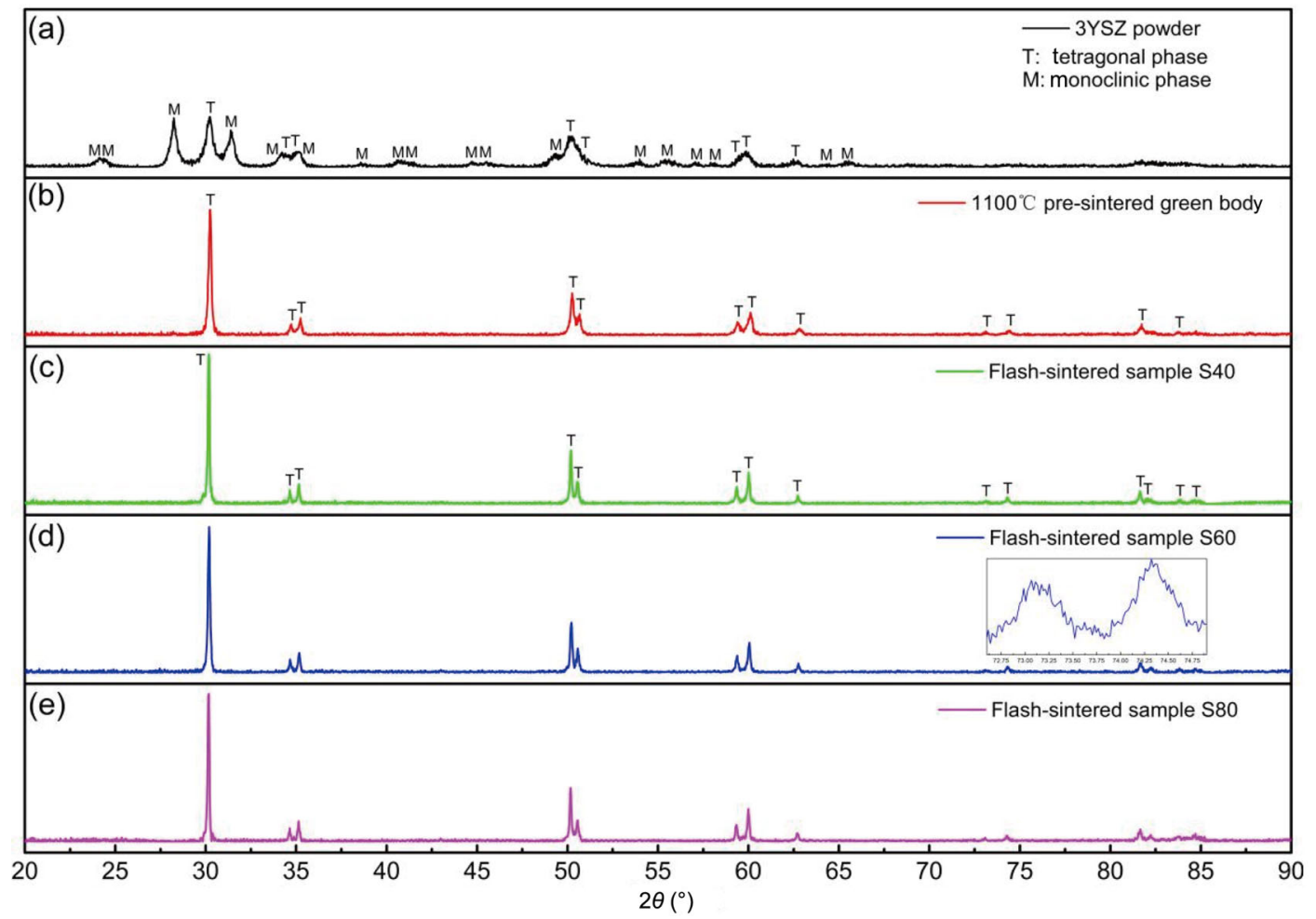

Fig. 8 XRD spectra of (a) 3 YSZ powder, (b) $1100{ }^{\circ} \mathrm{C}$ pre-sintered green body, (c) sample S40, (d) sample S60, and (e) sample S80.

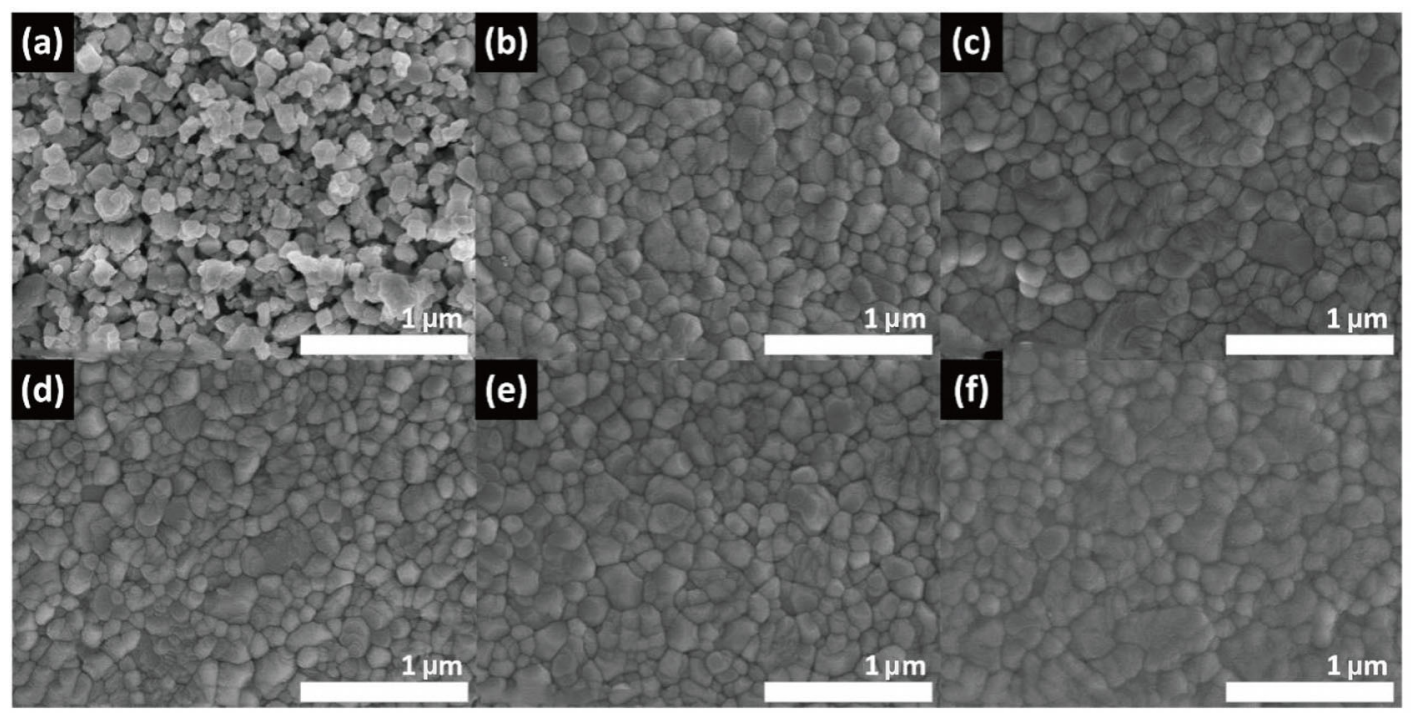

Fig. 9 SEM images of (a) green bodies before pre-sintering and polished surfaces of (b) S20, (c) S40, (d) S60, (e) S80, and (f) $\mathrm{S} 100-2$.

higher than 97\%. According to Figs. 9(b)-9(f), the average grain sizes of the flash-sintered samples are approximately $180 \mathrm{~nm}$, which is only six times the average grain size of the initial powder with an average grain size of $30 \mathrm{~nm}$. Therefore, the grains only undergo moderate growth during the pre-sintering and flash sintering processes. Meanwhile, Figs. 9(b)-9(f) show that some grains merge with each other, and their grain boundaries appear dimmer, indicating that the grains are still growing although the samples are fully densified when flash sintering stops.

Figure 10 shows the polished and thermally etched cross-sections of S20, S60, and S100-2. The interior of the sintered 3 YSZ is fully compacted by grains, and 


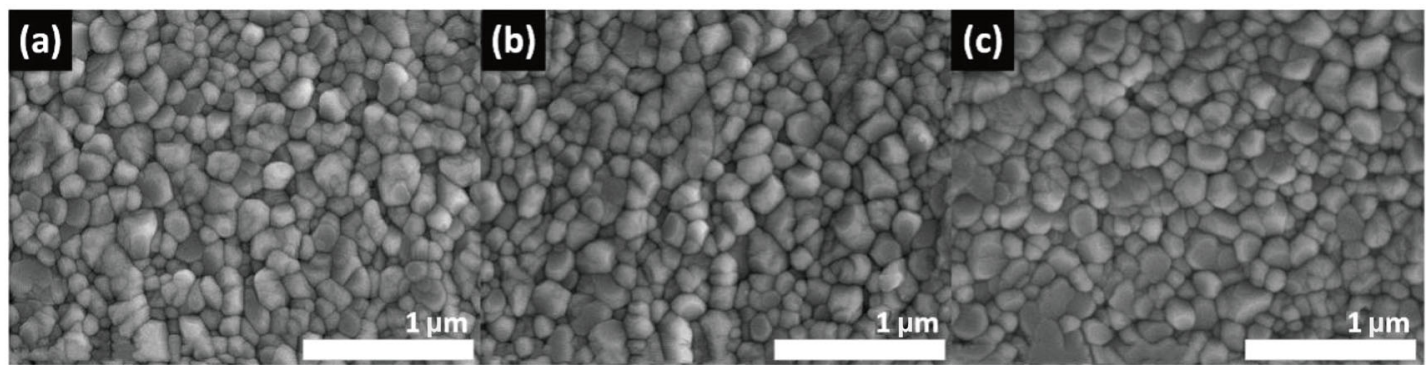

Fig. 10 SEM images of the cross-sections of polished (a) S20, (b) S60, and (c) S100-2.

there is no obvious structural difference among the 3 YSZ samples sintered at different pressures. Nearly no pores are observed in Fig. 10 for relative densities of $>97 \%$, and the average grain sizes are $<200 \mathrm{~nm}$, which is similar to that of the polished surfaces in Fig. 9.

\section{Conclusions}

In this study, by conducting room-temperature flash sintering at a low pressure, we successfully sintered high-density 3 YSZ. It is likely that the surface flashover leads to room-temperature flash sintering, and the onset electric field strength decreases with decreasing air pressure. Additional research should be conducted to further explore the optimal technological parameters of YSZ flash sintering, and find other ceramics whose flash sintering can be induced at room temperature. Nevertheless, our results expand the application scope of flash sintering. However, $80 \mathrm{kPa}$ is not a very low atmospheric pressure, and it can be reached in many plateau cities such as Kunming, where electric power is abundant. Therefore, considering the availability of plentiful electric power sources and suitable atmospheric pressure in such areas, energy-efficient full-electric sintering of YSZ could be achieved in the future.

\section{Acknowledgements}

This work was supported by the National Natural Science Foundation of China (No. 52077118), the Guangdong Basic and Applied Basic Research Foundation (No. 2021A1515011778), and the State Key Laboratory of New Ceramics and Fine Processing Tsinghua University (No. KFZD201903).

\section{References}

[1] Cologna M, Rashkova B, Raj R. Flash sintering of nanograin zirconia in $<5 \mathrm{~s}$ at $850{ }^{\circ} \mathrm{C} . \mathrm{J}$ Am Ceram Soc 2010, 93: 3556-3559.

[2] Prette ALG, Cologna M, Sglavo V, et al. Flash-sintering of $\mathrm{Co}_{2} \mathrm{MnO}_{4}$ spinel for solid oxide fuel cell applications. $J$ Power Sources 2011, 196: 2061-2065.

[3] Biesuz M, Sglavo VM. Flash sintering of alumina: Effect of different operating conditions on densification. J Eur Ceram Soc 2016, 36: 2535-2542.

[4] Zhang YY, Nie JY, Luo J. Effects of phase and doping on flash sintering of $\mathrm{TiO}_{2}$. J Ceram Soc Jpn 2016, 124: 296-300.

[5] Shi RK, Pu YP, Wang W, et al. Flash sintering of barium titanate. Ceram Int 2019, 45: 7085-7089.

[6] Cui B, Niu JP, Peng P, et al. Flash sintering preparation and electrical properties of $\mathrm{ZnO}-\mathrm{Bi}_{2} \mathrm{O}_{3}-\mathrm{M}\left(\mathrm{M}=\mathrm{Cr}_{2} \mathrm{O}_{3}, \mathrm{MnO}_{2}\right.$ or $\mathrm{Co}_{2} \mathrm{O}_{3}$ ) varistor ceramics. Ceram Int 2020, 46: $14913-$ 14918 .

[7] Ren K, Liu JL, Wang YG. Flash sintering of yttriastabilized zirconia: Fundamental understanding and applications. Scripta Mater 2020, 187: 371-378.

[8] Peng P, Deng YJ, Niu JP, et al. Fabrication and electrical characteristics of flash-sintered $\mathrm{SiO}_{2}$-doped $\mathrm{ZnO}-\mathrm{Bi}_{2} \mathrm{O}_{3}-$ $\mathrm{MnO}_{2}$ varistors. J Adv Ceram 2020, 9: 683-692.

[9] Zhou XB, Jing L, Kwon YD, et al. Fabrication of $\mathrm{SiC}_{\mathrm{w}} / \mathrm{Ti}_{3} \mathrm{SiC}_{2}$ composites with improved thermal conductivity and mechanical properties using spark plasma sintering. $J$ Adv Ceram 2020, 9: 462-470.

[10] Carvalho SGM, Muccillo ENS, Muccillo R. AC electric field assisted pressureless sintering zirconia: $3 \mathrm{~mol} \%$ yttria solid electrolyte. Phys Status Solidi A 2018, 215: 1700647.

[11] Guo L, Xin H, Zhang Z, et al. Microstructure modification of $\mathrm{Y}_{2} \mathrm{O}_{3}$ stabilized $\mathrm{ZrO}_{2}$ thermal barrier coatings by laser glazing and the effects on the hot corrosion resistance. $J$ Adv Ceram 2020, 9: 232-242.

[12] Fergus JW. Electrolytes for solid oxide fuel cells. J Power Sources 2006, 162: 30-40.

[13] Xing BH, Cao CR, Zhao WM, et al. Dense $8 \mathrm{~mol} \%$ yttriastabilized zirconia electrolyte by DLP stereolithography. $J$ Eur Ceram Soc 2020, 40: 1418-1423.

[14] M'Peko JC, Francis JSC, Raj R. Impedance spectroscopy and dielectric properties of flash versus conventionally sintered yttria-doped zirconia electroceramics viewed at the microstructural level. J Am Ceram Soc 2013, 96: 37603767.

[15] Christian KH, Charalambous H, Jha SK, et al. Current- 
ramp assisted sintering of 3YSZ: Electrochemical and microstructural comparison to flash and thermal sintering. $J$ Eur Ceram Soc 2020, 40: 436-443.

[16] Zhou HY, Li X, Zhu YC, et al. Review of flash sintering with strong electric field. High Volt 2022, https://doi.org/ 10.1049/hve2.12080.

[17] Downs JA, Sglavo VM. Electric field assisted sintering of cubic zirconia at $390{ }^{\circ} \mathrm{C} . \mathrm{J}$ Am Ceram Soc 2013, 96: 13421344.

[18] Yadav D, Raj R. Two unique measurements related to flash experiments with yttria-stabilized zirconia. J Am Ceram Soc 2017, 100: 5374-5378.

[19] Liu JM, Zhu YC, Wang XL, et al. Flash sintering of 8YSZ ceramics under AC fiel. In: Proceedings of the 2019 IEEE Conference on Electrical Insulation and Dielectric Phenomena, Richland, USA, 2019: 710-712.

[20] Steil MC, Marinha D, Aman Y, et al. From conventional ac flash-sintering of YSZ to hyper-flash and double flash. $J$ Eur Ceram Soc 2013, 33: 2093-2101.

[21] Yang D, Conrad H. Enhanced sintering rate of zirconia (3Y-TZP) by application of a small AC electric field. Scripta Mater 2010, 63: 328-331.

[22] Baraki R, Schwarz S, Guillon O. Effect of electrical field/current on sintering of fully stabilized zirconia. $J \mathrm{Am}$ Ceram Soc 2012, 95: 75-78.

[23] Conrad H, Wang J. Equivalence of AC and DC electric field on retarding grain growth in yttria-stabilized zirconia. Scripta Mater 2014, 72-73: 33-34.

[24] Muccillo R, Muccillo ENS. Shrinkage control of yttriastabilized zirconia during ac electric field-assisted sintering. J Eur Ceram Soc 2014, 34: 3871-3877.

[25] Qin W, Yun J, Thron AM, et al. Temperature gradient and microstructure evolution in AC flash sintering of $3 \mathrm{~mol} \%$ yttria-stabilized zirconia. Mater Manuf Process 2017, 32: 549-556.

[26] Charalambous H, Jha SK, Okasinski J, et al. Spectral analysis and temperature measurement during flash sintering under AC electric field. Materialia 2019, 6: 100273.

[27] Muccillo R, Kleitz M, Muccillo ENS. Flash grain welding in yttria stabilized zirconia. J Eur Ceram Soc 2011, 31: 1517-1521.

[28] Chaim R. Relations between flash onset-, Debye-, and glass transition temperature in flash sintering of oxide nanoparticles. Scripta Mater 2019, 169: 6-8.

[29] Biesuz M, Luchi P, Quaranta A, et al. Theoretical and phenomenological analogies between flash sintering and dielectric breakdown in $\alpha$-alumina. J Appl Phys 2016, 120: 145107.

[30] Shi RK, Pu YP, Ji JM, et al. Correlation between flash sintering and dielectric breakdown behavior in donor-doped barium titanate ceramics. Ceram Int 2020, 46: 12846-12851.

[31] Liu JM, Li X, Wang XL, et al. Alternating Current field flash sintering $99 \%$ relative density $\mathrm{ZnO}$ ceramics at room temperature. Scripta Mater 2020, 176: 28-31.

[32] Liu JM, Huang RX, Zhang RB, et al. Mechanism of flash sintering with high electric field: In the view of electric discharge and breakdown. Scripta Mater 2020, 187: 93-96.

[33] Liu DG, Cao YJ, Liu JL, et al. Effect of oxygen partial pressure on temperature for onset of flash sintering 3 YSZ. $J$ Eur Ceram Soc 2018, 38: 817-820.

[34] Zhang YY, Luo J. Promoting the flash sintering of $\mathrm{ZnO}$ in reduced atmospheres to achieve nearly full densities at furnace temperatures of $<120{ }^{\circ}$ C. Scripta Mater 2015, 106: 26-29.

[35] Kawamura T, Ishii M, Akbar M, et al. Pressure dependence of DC breakdown of contaminated insulators. IEEE Trans Electr Insul 1982, EI-17: 39-45.

[36] Rudakova VM, Tikhodeev NN. Influence of low air pressure on flashover voltages of polluted insulators: Test data, generalization attempts and some recommendations. IEEE Trans Power Deliv 1989, 4: 607-613.

[37] Zhang CY, Wang LM, Guan ZC, et al. Pollution flashover performance of full-scale $\pm 800 \mathrm{kV}$ converter station post insulators at high altitude area. IEEE Trans Dielectr Electr Insul 2013, 20: 717-726.

[38] Zhang YY, Jung JI, Luo J. Thermal runaway, flash sintering and asymmetrical microstructural development of $\mathrm{ZnO}$ and $\mathrm{ZnO}-\mathrm{Bi}_{2} \mathrm{O}_{3}$ under direct currents. Acta Mater 2015, 94: 87-100.

[39] Wang XL, Zhu YC, Huang RX, et al. Flash sintering of $\mathrm{ZnO}$ ceramics at $50{ }^{\circ} \mathrm{C}$ under an AC field. Ceram Int 2019, 45: 24909-24913.

[40] Naik K, Jha SK, Raj R. Correlations between conductivity, electroluminescence and flash sintering. Scripta Mater 2016, 118: $1-4$.

[41] Zhang YY, Nie JY, Chan JM, et al. Probing the densification mechanisms during flash sintering of $\mathrm{ZnO}$. Acta Mater 2017, 125: 465-475.

[42] Todd RI, Zapata-Solvas E, Bonilla RS, et al. Electrical characteristics of flash sintering: Thermal runaway of Joule heating. J Eur Ceram Soc 2015, 35: 1865-1877.

[43] Lacey AA, Hewitt IJ, Todd RI. A mathematical model for flash sintering. Math Model Nat Phenom 2015, 10: 77-89.

[44] Biesuz M, Sglavo VM. Flash sintering of ceramics. J Eur Ceram Soc 2019, 39: 115-143.

[45] Zhang ZJ. Study on pollution flashover performance and DC discharge model of insulator (long) strings at low air pressure. Ph.D. Thesis. Chongqing, China: Chongqing University, 2007.

[46] Sima WX, Tan W, Yang Q, et al. Long AC arc movement model for parallel gap lightning protection device with consideration of thermal buoyancy and magnetic force. Chin Soc Elec Eng 2011, 31: 138-145. (in Chinese)

[47] Li YK. Study of the influence of altitude on the characteristics of the electrical arc on polluted ice surface. Ph.D. Thesis. Québec, Canada: University of Québec, 2002.

[48] Saidi M, Abardeh RH. Air pressure dependence of naturalconvection heat transfer. In: Proceedings of the World Congress on Engineering 2010, Vol II, London, 2010.

[49] Wolten GM. Diffusionless phase transformations in 
zirconia and hafnia. J Am Ceram Soc 1963, 46: 418-422.

[50] Andrievskaya ER, Kovylyaev VV, Lopato LM, et al. Liquidus surface of the $\mathrm{ZrO}_{2}-\mathrm{Y}_{2} \mathrm{O}_{3}-\mathrm{Eu}_{2} \mathrm{O}_{3}$ phase diagram. Powder Metall Met Ceram 2014, 53: 312-322.

[51] Xie ZP, Xue WJ. Effect of $\mathrm{Y}_{2} \mathrm{O}_{3}$ contents and grain sizes on the mechanical properties and transformation of zirconia ceramics at cryogenic temperatures. Rare Metal Mat Eng 2013, 42: 256-259.

Open Access This article is licensed under a Creative Commons Attribution 4.0 International License, which permits use, sharing, adaptation, distribution and reproduction in any medium or format, as long as you give appropriate credit to the original author(s) and the source, provide a link to the Creative Commons licence, and indicate if changes were made.

The images or other third party material in this article are included in the article's Creative Commons licence, unless indicated otherwise in a credit line to the material. If material is not included in the article's Creative Commons licence and your intended use is not permitted by statutory regulation or exceeds the permitted use, you will need to obtain permission directly from the copyright holder.

To view a copy of this licence, visit http://creativecommons. org/licenses/by/4.0/. 